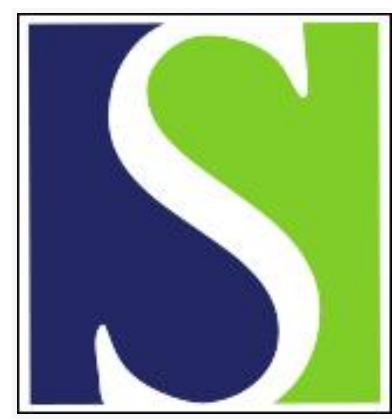

Scand J Work Environ Health 2011;37(6):512-524

https://doi.org/10.5271/sjweh.3166

Published online: 27 Apr 2011, Issue date: Nov 2011

Comparison of two different methods for performing combination analysis of force and posture risk factors in an epidemiological study

by Bao S, Howard N, Spielholz P, Silverstein B, Polissar N

Affiliation: Safety \& Health Assessment \& Research for Prevention (SHARP) Program, Washington State Department of Labor and Industries, PO Box 44330, Olympia, WA 98504, USA. baos235@Ini.wa.gov

Refers to the following texts of the Journal: 2002;28(4):222-231 2006;32(2):99-108 2009;35(2):113-126

Key terms: analysis of force; carpal tunnel syndrome; CTS; epidemiology; exposure analysis; force; MSD; musculoskeletal disorder; observation method; posture; risk factor; upper-extremity musculoskeletal disorder

This article in PubMed: www.ncbi.nlm.nih.gov/pubmed/21526328 


\title{
Comparison of two different methods for performing combination analysis of force and posture risk factors in an epidemiological study
}

\author{
by Stephen Bao, PhD, ${ }^{1}$ Ninica Howard, MSc, ${ }^{1}$ Peregrin Spielholz, PhD, ${ }^{2}$ Barbara Silverstein, PhD, ${ }^{1}$ and \\ Nayak Polissar, $\mathrm{PhD}^{3}$
}

Bao S, Howard N, Spielholz P, Silverstein B, Polissar N. Comparison of two different methods for performing combination analysis of force and posture risk factors in an epidemiological study. Scand J Work Environ Health. 2011;37(6):512-524. doi:10.5271/sjweh.3166

\begin{abstract}
Objectives This study aimed to introduce a method of simultaneous combination analysis of multiple exposure parameters for large epidemiological studies of work-related upper-extremity musculoskeletal disorders (MSD) and compare this analysis method with the conventionally used job-level combination analysis method when applied in exposure-response analysis of work-related upper-extremity MSD.

Methods Health outcome [carpal tunnel syndrome (CTS)] and physical exposure (forceful exertion and hand/wrist postures) data for 733 subjects were obtained from the baseline period of a 3-year work-related upper-extremity MSD study. Determinations of CTS cases were done based on a set of defined criteria. Physical exposure variables of several different types of forceful exertions and three different hand/wrist postures were collected onsite, processed, and analyzed using both a simultaneous combination and job-level combination analysis method.
\end{abstract}

Results The commonly used job-level combination analysis method resulted in significantly different combination exposure distributions compared to the simultaneous combination analysis method, although the absolute differences were small. Both methods showed some significantly higher combined force-posture exposures among CTS cases than non-cases.

Conclusions The simultaneous combination method provides more realistic distribution information on combined exposure parameters compared to the job-level combination method that has been commonly used in epidemiological studies. The newly developed simultaneous combination analysis method needs to be used in larger scale work-related upper-extremity MSD epidemiological studies to test its predictive power compared to the job-level combination analysis method.

Key terms carpal tunnel syndrome; CTS; exposure analysis; MSD; musculoskeletal disorder; observation method; upper-extremity musculoskeletal disorder.

Many epidemiological studies of upper-extremity musculoskeletal disorders (MSD) consider multiple exposure factors, such as forceful exertions and hand/wrist postures (1-4). Often these multiple exposure factors are collected independently and their combined effect on a health outcome is considered in the modeling stage at the job-level, ie, whether forceful exertions and awkward wrist postures occurred in a job. We label this type of analysis as "job-level" combination analysis in this paper. Job-level combination analysis of risk factors does not distinguish whether the risk factors occur at the same time (simultaneously) or at different times during job performance.
When multiple instrumentations are used in biomechanics/ergonomics research, several physiological and physical measurements are usually recorded simultaneously (5), which often allow researchers to analyze for simultaneous exposures. In ergonomic applications, some physical parameters are simultaneously considered through calculations, such as the National Institute for Occupational Safety and Health (NIOSH) lifting equation (6), the University of Michigan 3-D static strength prediction program (7) and the Ohio State University lumbar motion monitor model (5). However, some physical exposure parameters, such as electromyography for muscle activities and eletrogoniometers/potential meters

1 Safety \& Health Assessment \& Research for Prevention (SHARP) Program, Washington State Department of Labor and Industries, WA, USA.

2 Sound Transit, Seattle, WA, USA.

3 The Mountain-Whisper-Light Statistical Consulting, Seattle, WA, USA.

Correspondence to: Stephen Bao, Safety \& Health Assessment \& Research for Prevention (SHARP) Program, Washington State Department of Labor and Industries, PO Box 44330, Olympia, WA 98504, USA. [E-mail: baos235@lni.wa.gov] 
for joint angles $(8,9)$, are recorded simultaneously, but summarized individually at the job-level. Their combined effects on health outcomes are considered later in the analysis at the job-level. As far as we know, the approach of simultaneous consideration of multiple exposure factors has not been used in epidemiological studies of upper-extremity musculoskeletal risk factors and disorders where exposure quantification is based on observational methods, although self-reporting tools sometimes do consider whether multiple exposures occur at the same time or not. Instead most researchers have used the job-level combination approach in the modeling stage when a combination term of multiple exposure factors is included in the statistical models when multiple exposure factors are studied (4).

Although it is easy to understand that a job with both awkward hand/wrist postures and high hand-forceful exertions usually has higher injury risk than a job with either awkward postures or high hand-forceful exertions [as documented in one of the NIOSH review documents (10)], the consideration of multiple exposure factors at the job-level may not accurately categorize the job risks. The ideas of considering multiple exposure factors were previously proposed by Drury (11), who described a daily damaging wrist motions index which counted the number of times hand grip forces were exerted simultaneously during wrist flexions. The following example illustrates the problem with the job-level combination analysis. Let us consider only two physical exposure factors: force and posture in two jobs [A and B (figure 1)]. To simplify the illustration, force and posture have only two levels each, (high and low and poor and good, respectively). The exposures for both jobs A and $\mathrm{B}$ according to the job-level combination analysis can appear the same, ie, both jobs have high force and poor posture exposures $30 \%$ of the time. However, the exposures for jobs $\mathrm{A}$ and $\mathrm{B}$ can be different according to the simultaneous combination analysis, ie, job A has $30 \%$ high force and $30 \%$ poor posture exposure, but they do not happen at the same time. In contrast, Job B has 30\% high force and 30\% poor posture exposure, and both risk factors occur at the same time. According to the NIOSH review document (10), the existence of the multiple risk factors increases the MSD risks. However, that review did not specify whether the multiple risk factors occurred simultaneously or at different times. Conceptually, job B may have different risk of injuries compared to job A, according to the simultaneous combination analysis. This difference is not captured in the job-level combination analysis.

The objectives of this paper were, on the one hand, to demonstrate a method of simultaneous combination analysis used to collect multiple risk factors from a field epidemiological study and, on the other hand, compare the distribution results of force and posture combina- tions of different categories between this simultaneous combination analysis and a job-level combination analysis. As an application example, we also compared combination exposure distributions among cases of carpal tunnel syndrome (CTS) and non-cases for each of the combination analysis methods. The hypothesis was that the job-level combination analysis may have provided insufficient information about the combined exposures compared to the simultaneous combination exposure analysis. This information may be useful in studying exposure-response relationships for upper extremity MSD.

\section{Methods}

For this paper, we used health outcome in terms of CTS status and physical exposure data for 733 subjects at baseline from a 3-year prospective upper-extremity MSD study $(4,12,13)$. These subjects were from 12 different worksites in the manufacturing and healthcare sectors including many varied jobs such as assembly, fabrication, welding, painting, pharmacy, office, etc. Among the 733 subjects, $52.3 \%$ were males with an average age of 37.4 years [standard deviation (SD) 11.4] and 2.1 years in the current job ( $1^{\text {st }}-3^{\text {rd }}$ quartile: $\left.0.5-5.4\right)$ compared to the average female age of 41.7 years (SD $10.0)$ and 2.5 years in the current job $\left(1^{\text {st }}-3^{\text {rd }}\right.$ quartile: 0.9-5.3). Only health outcomes and physical exposure data of the dominant hand from the baseline collection are included in this paper.

The Washington State Institutional Review Board approved this study. Written consent (available in several different languages) was obtained from all subjects prior to data collection.

\section{Heath outcomes}

Since this paper focuses on the simultaneous combination risk factor analysis method, the exposure-response analysis was used as an application example of this method. Only one health outcome variable (ie, CTS) is used in this paper. Case definition for CTS cases is described in detail in the paper published by Silverstein et al (14). Case definition is based on (i) workers' responses to a structured questionnaire interview conducted by trained interviewers, (ii) results of a standardized physical examination performed by a trained health team staff member (physician, physical therapist, and registered nurse), and (iii) electro-diagnostic testing for median nerve slowing at the wrist reviewed by a board certified neurologist. CTS cases are defined as current symptoms and positive electro-diagnostic test in the same hand and no history of acute trauma to the hand/ 


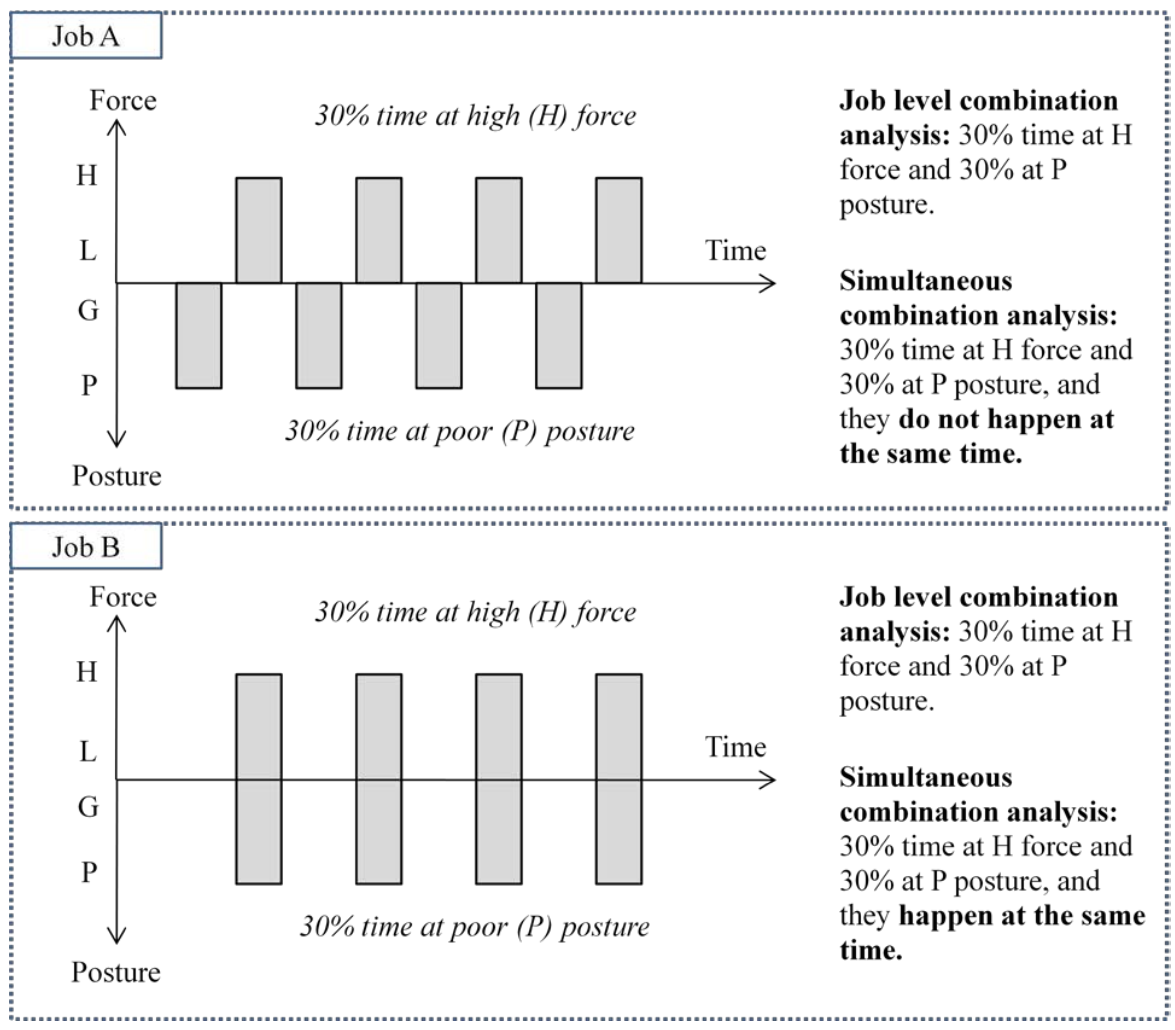

Figure 1. Job-level combination analysis does not show exposure differences between jobs $A$ and $B$, while the simultaneous combination analysis does. [H=high force, $\mathrm{L}=$ low force, $G=$ good posture, and $P=$ poor posture]. wrist or rheumatoid arthritis. Of the 733 subjects, 13 had missing information on their CTS status.

\section{Physical exposures}

During worksite visits, each worker was videotaped performing his or her job for a minimum of 15 minutes or at least 3 complete task cycles, whichever was longer. The sampling durations were longer for non-cyclic and multiple task jobs in order to obtain good representation of work activities of a typical work day. The average job recording time was 18.2 minutes (range: 15.0-32.1 minutes). Details of the sampling strategy can be found in our previous publications $(12,15)$. Two synchronized video cameras were used to capture both body sides of a subject. Activities involving forceful hand exertions were identified by ergonomists onsite during the video filming period. The amount of force used in each of these activities was quantified later by the ergonomists after the video filming $(12,15)$.

In order to quantify forceful exertions, five different types of forceful exertions were identified. They were lifting/lowering (no distinction was made between them), pushing/pulling (no distinction was made between them), pinch gripping, power gripping, and "other" forceful exertions. "Other" type of forceful exertions were those forces that were neither pinch nor power gripping hand exertions, neither lifting/lowering nor pushing or pulling forces. Examples of this type of exertions included pressing down with fingers (usually the thumb pressing in operating controls or snapping parts into place, holding a chisel), one-hand pulling or pushing (a band tightening tool or an object in a seated position), pushing down with the hands, pushing with a few fingers (plywood sheets into a press machine), and lifting with only a few fingers without using a pinch grip (linen in a laundry). Although more than one type of forces could occur at the same time (eg, lifting with a power grip), only one type of force was chosen for the analysis in this paper. A determination of choices was made based on the type of activities. If an exertion activity was a manual material handling type, lifting/ lowering and pushing/pulling force values were used instead of hand grip forces. If an exertion activity was mainly a hand-intensive activity, power/pinch gripping force values were used.

The force measurements were obtained by using force gauges for lifting, pushing and pulling forces, and by force matching using grip dynamometers for pinch and power gripping forces (16). Forces other than these force types were quantified using either force gauges or grip dynamometers depending on the situations.

The recorded task activities were later digitized and processed in laboratory. A detailed time study was conducted for each of the measured forceful-hand exertions using the multi-video task analysis (MVTA) program 
(17) to obtain the start and end points of each of the identified forceful exertion activities. Periods when a subject was not performing one of these forceful exertions were labeled as non-forceful activities. This detailed time study was performed by the ergonomists. The video recordings were replayed at slow speed if necessary for the ergonomists to see task performance details and assist the activity markings. These points were identified by their frame numbers of the recorded task video clips.

The same digitized video recordings were also processed using a posture analysis program (18) to quantify the hand/wrist postures of randomly selected video frames (a minimum of 75 frames per job). This provided the possibility to synchronize the forceful exertions/ non-forceful activities and the hand/wrist postures. The estimated postures were originally recorded in degrees of angles and then grouped by postural categories in the data processing stage. Each of the postures corresponded to a specific moment during a task performance and was uniquely identifiable by the frame number of the video clip. For the purpose of this paper, posture parameters of only the forearm pronation/supination, wrist flexion/ extension and wrist ulnar/radial deviation were used.

In order to perform the simultaneous multiple risk factor combination analysis, both of the original forceful exertion and work posture data were converted into exposure categories. Forceful exertions were categorized as high, medium, or low forces for each of the force types. Non-forceful activities were considered as a separate exertion category. The postures were dichotomized into good and poor postures. The cut-off points for both the forceful exertions and postures are listed in tables $1 \mathrm{a}$ and $1 \mathrm{~b}$. These cut-off points were made according to unpublished univariate analysis results from the large work-related, upper-extremity MSD epidemiological study and some commonly used cut-off points found in the literature (19-22).

Since the forceful exertion and work posture analyses were based on the same video recordings, they were synchronized by frame number. Therefore, for the simultaneous multiple risk factor combination method, the analysis was performed by examining both posture and forceful exertion categories at each of the video frames. New combination exposure variables were then created that included four forceful exertion categories (high-, medium-, low- and non-forceful activity) and two work posture categories (good and poor) for each of the five types of forceful exertions (lift/lower, push/pull, power grip, pinch grip, and other forceful exertions) and each of the three posture parameters (forearm pronation/supination, wrist flexion/extension, and wrist ulnar/radial deviation). In other words, we got $5 \times 3$ (types of forceful exertions $\times$ posture parameters) variables that each took $4 \times 2$ (exertion categories $\times$ posture categories) values.

The job-level combination analysis was performed by calculating distributions of forceful exertions and work postures separately at the job-level irrespective whether they occurred at the same time or not. The actual consideration of their combined effects was done at the statistical analysis stage (see details below).

\section{Further data processing and statistical analysis}

Distributions of forceful exertions and hand/wrist postures were computed separately for each of the 733 subjects for the job-level combination analysis, and the simultaneous exposure combination analysis variables. Means and standard deviations of these distributions were calculated for the whole study population.

Table 1a. Categorization of forceful exertions.

\begin{tabular}{|c|c|c|c|c|c|c|}
\hline & \multicolumn{2}{|c|}{ High } & \multicolumn{2}{|c|}{ Medium } & \multicolumn{2}{|c|}{ Low } \\
\hline & Pounds & Newtons & Pounds & Newtons & Pounds & Newtons \\
\hline \multicolumn{7}{|l|}{ Forceful exertions per hand } \\
\hline Lift/lower & $\geq 10$ & $\geq 44.5$ & $\geq 5-<10$ & $\geq 22.3-<44.5$ & $>0-<5$ & $>0.0-<22.3$ \\
\hline Push/pull & $\geq 12$ & $\geq 53.4$ & $\geq 5-<12$ & $\geq 22.3-<53.4$ & $>0-<5$ & $>0.0-<22.3$ \\
\hline Power grip & $\geq 29$ & $\geq 129.1$ & $\geq 10-<29$ & $\geq 44.5-<129.3$ & $>0-<10$ & $>0.0-<44.5$ \\
\hline Pinch grip & $\geq 12$ & $\geq 53.4$ & $\geq 2-<12$ & $\geq 8.9-<53.4$ & $>0-<2$ & $>0.0-<8.9$ \\
\hline Other forceful exertions & $\geq 10$ & $\geq 44.5$ & $\geq 5-<10$ & $\geq 22.3-<44.5$ & $>0-<5$ & $>0.0-<22.3$ \\
\hline Non-forceful exertions & \multicolumn{6}{|c|}{ Any type force $=0$} \\
\hline
\end{tabular}

Table 1b. Categorization of working postures.

\begin{tabular}{lll}
\hline & \multicolumn{1}{c}{ Poor (degrees) } & \multicolumn{1}{c}{ Good (degrees) } \\
\hline Working posture & & Between $45^{\circ}$ supination $\& 45^{\circ}$ pronation \\
Forearm pronation/supination & $\geq 45^{\circ}$ supination or $\geq 45^{\circ}$ pronation & Between $45^{\circ}$ extension \& $15^{\circ}$ flexion \\
Wrist flexion/extension & $\geq 45^{\circ}$ extension or $\geq 15^{\circ}$ flexion & Between $5^{\circ}$ radial deviation \& $20^{\circ}$ ulnar deviation \\
Wrist ulnar/radial deviation & $\geq 20^{\circ}$ ulnar deviation or $\geq 5^{\circ}$ radial deviation & \\
\hline
\end{tabular}


Frequency distributions of the exposure combination variables for the cases and non-cases of CTS were also calculated respectively.

In order to compare the job-level and simultaneous combination analysis methods when used in categorizing posture and forceful exertion exposures, we compared the distributions of the various posture and forceful exertion categories obtained by these two methods. The joblevel combination analysis method collected posture and forceful exertion variables independently to each other at the job level. There were 16 exertion categories, ie, three exertion categories (low, medium and high force) for each of the five types of exertions plus non-forceful activity, and two posture categories (good and poor postures) for each of the three hand/wrist posture variables. For the simultaneous combination analysis, there were 32 posture-exertion combination categories for each of the three hand/wrist postures.

There were no direct ways to compare the distributions of the combination exposure variables obtained from these two analysis methods due to their different formulations. However, the job-level combination analysis method assumed that the posture and forceful exertion variables were independent of each other. In keeping with this independence and in order to compare the exposure distributions resulting from the two different methods, we combined the job-level posture and forceful exertion variables in an interaction format that preserved the underlying assumption of independent recording. To explain this approach, we use the variables of the present study as an example. Let us define $\mathrm{E}_{\mathrm{i}, \mathrm{job}}$ as the percent of time that the $i$-th forceful exertion category $(i=1,2, \ldots, 16)$ at the job-level, and $\mathrm{P}_{\mathrm{j}, \mathrm{job}}$ as the percent of time of the $j$-th posture category $(j=1,2)$ for a particular hand/wrist posture at the job-level, then:

$$
\mathrm{EP}_{\mathrm{ij}, \mathrm{job}}=\mathrm{E}_{\mathrm{i}, \mathrm{job}} \times \mathrm{P}_{\mathrm{j}, \mathrm{job}}
$$

can be defined as the expected proportion of percent time spent in the combination of the exertion category $i$ occurring with posture category $j$. We note that the independent recording of posture and exertion does not assume that there is no statistical interaction of these two job-level variables as, say, risk factors for injury. However, the interaction terms for such an analysis would be constructed in the way we have just described.

As a simple example, consider a study with just two forceful exertion categories: no force and force present, along with two posture categories: good and poor. A job-level study found that a worker spent $90 \%$ and $10 \%$ time without and with force, respectively. In the same study, the postures were $70 \%$ and $30 \%$ good and poor, respectively. Under the independence of force and posture, there would be $63 \%$ of the time expected with no force and good posture. $(63 \%=0.9 \times 0.7 \times 100 \%$. $)$
The other percentages would be an expected $27 \%$ of the time in no force/poor posture, $7 \%$ in force/good posture and $3 \%$ in force/poor posture. The sum across the four categories is $100 \%$ of the worker's time.

Using this method, we calculated these expected job-level percentages in 32 categories to correspond to the 32 categories obtained from the simultaneous combination analysis method for each type of postures. For the job-level 32 categories and separately for the simultaneous combination analysis method's 32 categories, we pooled all subjects, regardless of case/control status, and compared the job-level to the simultaneous percentages for each of the 32 categories using the Wilcoxon Signed Ranks test. We calculated the simple difference of means for each category as well as the ratio of means as descriptive statistics. We also compared the percentages in each category between the CTS cases and the non-cases using the Mann-Whitney test. We again calculated the differences and ratios of means as descriptive statistics.

Since the ratios of percentages (good posture/poor posture) will converge toward 1.0 as the two percentages, time in good (P1) and poor postures (P2), approach $50 \%$, and because the no-force/good posture combination usually has very high percent of time (that was the nature of most jobs), we also constructed a new variable: ratios of $\mathrm{X} \%=(100-\mathrm{P} 1) /(100-\mathrm{P} 2)$. All the calculated ratios are particularly helpful in detecting differences between the two combination analysis methods. The P-values have not been adjusted for multiple comparisons, since it is of value to note which categories differ significantly between the two analysis methods rather than to test a single global hypothesis for which we would need a multiple testing adjustment. We understand that many confounding factors (eg, age, gender and body mass index) should be considered in musculoskeletal epidemiological analyses (14). We ignored their influences in all the analyses in the present paper in order to focus on the discussions of the two exposure combination analysis methods. All analyses were performed using the SAS statistical program (version 9E, SAS Institute, Cary, NC, USA).

\section{Results}

Means and SD of forceful exertion and hand/wrist posture distributions obtained by the two combination analysis methods are shown in tables $2 \mathrm{a}, \mathrm{b}$, and $\mathrm{c}$ for the three different hand/wrist postures respectively. Overall, the study population had only spent a small proportion of their time on high forceful exertions of the various types. For example, on average high lifting/ lowering force occurred only about $2 \%$ of the time (ie, 
Table 2a. Comparison of posture-exertion combination distributions between the job level and simultaneous analysis methods (forearm pronation/supination) $\mathrm{N}=733$. [SD=standard deviation.]

\begin{tabular}{|c|c|c|c|c|c|c|c|c|c|}
\hline \multirow{2}{*}{$\begin{array}{l}\text { Exertion type and category } \\
\text { (no, low, medium or } \\
\text { high exertion) }\end{array}$} & \multirow{2}{*}{$\begin{array}{l}\text { Posture } \\
\text { category }\end{array}$} & \multicolumn{2}{|c|}{$\%$ time } & \multicolumn{2}{|l|}{$\%$ time } & \multicolumn{2}{|c|}{ Delta $^{a}$} & \multirow[t]{2}{*}{ Ratio b } & \multirow[t]{2}{*}{$\mathrm{P}$-value ${ }^{c}$} \\
\hline & & Job-level & SD & Simultaneous & SD & Mean & SD & & \\
\hline \multicolumn{10}{|l|}{ Non-forceful activity } \\
\hline No & Good & 79.12 & 18.57 & 79.75 & 18.22 & 0.64 & 2.89 & 1.01 & $<0.001$ \\
\hline No & Poor & 5.19 & 5.38 & 4.72 & 5.36 & -0.51 & 2.46 & 0.91 & $<0.001$ \\
\hline \multicolumn{10}{|c|}{ Non-forceful activity $(100-X \%)^{d}$} \\
\hline No & Good & 20.88 & 18.57 & 20.25 & 18.22 & -0.64 & 2.89 & 0.97 & $<0.001$ \\
\hline \multicolumn{10}{|l|}{ Lift/lower } \\
\hline Low & Good & 3.50 & 8.86 & 3.31 & 8.63 & -0.23 & 1.4 & 0.94 & \\
\hline Low & Poor & 0.32 & 1.07 & 0.56 & 2.07 & 0.24 & 1.35 & 1.79 & $<0.05$ \\
\hline Medium & Good & 1.74 & 4.85 & 1.51 & 4.41 & -0.18 & 0.95 & 0.87 & \\
\hline Medium & Poor & 0.19 & 0.81 & 0.36 & 1.36 & 0.18 & 0.95 & 1.92 & \\
\hline High & Good & 1.81 & 4.85 & 1.51 & 4.30 & -0.28 & 1.47 & 0.84 & $<0.05$ \\
\hline High & Poor & 0.19 & 0.63 & 0.47 & 1.86 & 0.28 & 1.47 & 2.50 & $<0.05$ \\
\hline \multicolumn{10}{|l|}{ Push/pull } \\
\hline Low & Good & 0.28 & 2.52 & 0.29 & 2.55 & 0.00 & 0.39 & 1.01 & $<0.05$ \\
\hline Low & Poor & 0.02 & 0.29 & 0.03 & 0.52 & 0.01 & 0.37 & 1.27 & $<0.05$ \\
\hline Medium & Good & 0.57 & 2.88 & 0.55 & 2.84 & -0.01 & 0.38 & 0.97 & \\
\hline Medium & Poor & 0.04 & 0.24 & 0.04 & 0.36 & 0.00 & 0.29 & 1.04 & $<0.05$ \\
\hline High & Good & 0.45 & 2.15 & 0.45 & 2.17 & -0.01 & 0.34 & 1.00 & $<0.01$ \\
\hline High & Poor & 0.03 & 0.19 & 0.02 & 0.24 & -0.01 & 0.23 & 0.63 & $<0.001$ \\
\hline \multicolumn{10}{|l|}{ Power grip } \\
\hline Low & Good & 0.37 & 2.35 & 0.35 & 2.26 & -0.03 & 0.49 & 0.93 & \\
\hline Low & Poor & 0.03 & 0.31 & 0.06 & 0.76 & 0.03 & 0.49 & 2.16 & \\
\hline Medium & Good & 1.64 & 7.08 & 1.67 & 7.26 & 0.03 & 0.41 & 1.02 & $<0.001$ \\
\hline Medium & Poor & 0.08 & 0.41 & 0.07 & 0.55 & -0.02 & 0.41 & 0.78 & $<0.001$ \\
\hline High & Good & 0.75 & 3.44 & 0.78 & 3.51 & 0.01 & 0.43 & 1.04 & $<0.001$ \\
\hline High & Poor & 0.06 & 0.32 & 0.05 & 0.52 & -0.01 & 0.43 & 0.84 & $<0.001$ \\
\hline \multicolumn{10}{|l|}{ Pinch grip } \\
\hline Low & Good & 0.07 & 1.21 & 0.07 & 1.23 & 0.00 & 0.14 & 0.99 & \\
\hline Low & Poor & 0.00 & 0.05 & 0.01 & 0.15 & 0.00 & 0.14 & 1.71 & \\
\hline Medium & Good & 1.28 & 4.29 & 1.28 & 4.34 & -0.02 & 0.53 & 1.00 & $<0.05$ \\
\hline Medium & Poor & 0.09 & 0.42 & 0.11 & 0.71 & 0.02 & 0.5 & 1.27 & \\
\hline High & Good & 1.63 & 5.48 & 1.52 & 5.53 & -0.06 & 0.92 & 0.94 & \\
\hline High & Poor & 0.18 & 0.95 & 0.24 & 1.36 & 0.06 & 0.92 & 1.33 & \\
\hline \multicolumn{10}{|l|}{ Other forces } \\
\hline Low & Good & 0.06 & 1.01 & 0.06 & 0.92 & -0.01 & 0.14 & 0.94 & \\
\hline Low & Poor & 0.00 & 0.04 & 0.01 & 0.17 & 0.01 & 0.14 & 2.74 & \\
\hline Medium & Good & 0.01 & 0.23 & 0.01 & 0.25 & 0.00 & 0.02 & 1.13 & \\
\hline Medium & Poor & 0.00 & 0.01 & 0.00 & 0.00 & 0.00 & 0.01 & 0.00 & \\
\hline High & Good & 0.13 & 1.35 & 0.12 & 1.23 & -0.01 & 0.25 & 0.95 & \\
\hline High & Poor & 0.01 & 0.14 & 0.02 & 0.38 & 0.01 & 0.25 & 2.01 & \\
\hline
\end{tabular}

a Delta: the difference between \% times obtained from the simultaneous method and the job-level method.

${ }^{b}$ Ratio: ratio of \% times obtained from the simultaneous method and the job-level method.

${ }^{c}$ Significance level notation: blank=not significant at $\mathrm{P}<0.05$ according to Wilcoxon Signed Ranks test.

${ }^{d} \mathrm{X} \%=(100-\mathrm{P} 1) /(100-\mathrm{P} 2)$, where $\mathrm{P} 1=$ good posture percentage, and $\mathrm{P} 2=$ poor posture percentage.

9.6 minutes in an 8-hour shift, tables 2a, b, and c). The proportions of times spent on high forceful exertions in combination with awkward hand/wrist postures were even lower. For example, high power grip forces together with awkward wrist flexion/extension postures occurred, on average, only $0.13 \%$ or $0.12 \%$ of the time depending on the job-level and simultaneous combination analysis methods respectively (table $2 \mathrm{~b}$ ). This translates to $<1$ minute in an 8 -hour work shift.

Comparing the distributions between the two combination analysis methods, some statistically significant differences were found (tables 2a, b, and c). Significances at different probability levels were noted in the table. Some of the distributions were highly significantly different $(\mathrm{P}<0.001)$ between the results obtained from the two different combination analysis methods (eg, distributions of times spent on non-forceful exertion activities, medium-to-high grip forces together with both good and poor forearm pronation/supination postures, and lifting/lowering and pushing/pulling forces with different wrist ulnar and radial deviation postures), although the absolute differences in terms of percentages of time were small $(<0.7 \%$ of the time).

As an application, these two combination analysis methods were used to quantify exposure distributions between subjects of CTS cases and non-cases. In the study population, there were 76 CTS cases, 644 noncases and 13 with unknown status. Tables $3 \mathrm{a}, \mathrm{b}$, and 
Table $\mathbf{2 b}$. Comparison of posture-exertion combination distributions between the job level and simultaneous analysis methods (wrist flexion and extension) $\mathrm{N}=733$. [SD=standard deviation.]

\begin{tabular}{|c|c|c|c|c|c|c|c|c|c|}
\hline \multirow{2}{*}{$\begin{array}{l}\text { Exertion type and category } \\
\text { (no, low, medium or } \\
\text { high exertion) }\end{array}$} & \multirow{2}{*}{$\begin{array}{l}\text { Posture } \\
\text { category }\end{array}$} & \multicolumn{2}{|c|}{$\%$ time } & \multicolumn{2}{|c|}{$\%$ time } & \multicolumn{2}{|c|}{ Delta $^{\text {a }}$} & \multirow[t]{2}{*}{ Ratio $^{b}$} & \multirow[t]{2}{*}{ P-value } \\
\hline & & Job-level & SD & Simultaneous & SD & Mean & SD & & \\
\hline \multicolumn{10}{|l|}{ Non-forceful activity } \\
\hline No & Good & 71.73 & 18.03 & 72.32 & 17.93 & 0.66 & 3.69 & 1.01 & $<0.001$ \\
\hline No & Poor & 12.58 & 8.89 & 12.15 & 9.37 & -0.54 & 3.18 & 0.97 & $<0.001$ \\
\hline \multicolumn{10}{|c|}{ Non-forceful activity $(100-\mathrm{X} \%)^{d}$} \\
\hline No & Good & 28.27 & 18.03 & 27.68 & 17.93 & -0.66 & 3.69 & 0.98 & $<0.001$ \\
\hline \multicolumn{10}{|l|}{ Lift/lower } \\
\hline Low & Good & 3.25 & 8.57 & 3.22 & 8.46 & -0.07 & 1.19 & 0.99 & \\
\hline Low & Poor & 0.57 & 1.42 & 0.65 & 1.91 & 0.08 & 1.16 & 1.15 & \\
\hline Medium & Good & 1.63 & 4.65 & 1.55 & 4.45 & -0.03 & 0.79 & 0.95 & \\
\hline Medium & Poor & 0.29 & 1.01 & 0.31 & 1.19 & 0.03 & 0.77 & 1.06 & \\
\hline High & Good & 1.68 & 4.64 & 1.59 & 4.61 & -0.07 & 0.99 & 0.95 & \\
\hline High & Poor & 0.32 & 0.93 & 0.39 & 1.45 & 0.07 & 0.97 & 1.23 & \\
\hline \multicolumn{10}{|l|}{ Push/pull } \\
\hline Low & Good & 0.24 & 2.05 & 0.23 & 2.18 & -0.01 & 0.37 & 0.96 & \\
\hline Low & Poor & 0.07 & 0.78 & 0.09 & 0.80 & 0.02 & 0.33 & 1.27 & \\
\hline Medium & Good & 0.51 & 2.63 & 0.48 & 2.59 & -0.02 & 0.43 & 0.94 & \\
\hline Medium & Poor & 0.10 & 0.51 & 0.11 & 0.72 & 0.01 & 0.43 & 1.13 & \\
\hline High & Good & 0.39 & 1.88 & 0.37 & 1.85 & -0.03 & 0.58 & 0.94 & \\
\hline High & Poor & 0.09 & 0.45 & 0.10 & 0.74 & 0.01 & 0.55 & 1.13 & \\
\hline \multicolumn{10}{|l|}{ Power grip } \\
\hline Low & Good & 0.33 & 2.02 & 0.35 & 2.04 & 0.01 & 0.3 & 1.06 & $<0.05$ \\
\hline Low & Poor & 0.08 & 0.61 & 0.07 & 0.72 & -0.01 & 0.29 & 0.85 & $<0.05$ \\
\hline Medium & Good & 1.48 & 6.42 & 1.40 & 6.09 & -0.08 & 1.17 & 0.95 & \\
\hline Medium & Poor & 0.25 & 1.13 & 0.34 & 1.96 & 0.09 & 1.17 & 1.37 & \\
\hline High & Good & 0.68 & 3.19 & 0.71 & 3.34 & 0.01 & 0.42 & 1.04 & \\
\hline High & Poor & 0.13 & 0.65 & 0.12 & 0.73 & -0.01 & 0.42 & 0.93 & \\
\hline \multicolumn{10}{|l|}{ Pinch grip } \\
\hline Low & Good & 0.07 & 1.16 & 0.07 & 1.25 & 0.00 & 0.13 & 1.05 & \\
\hline Low & Poor & 0.01 & 0.10 & 0.01 & 0.14 & 0.00 & 0.13 & 0.82 & \\
\hline Medium & Good & 1.15 & 3.99 & 1.15 & 4.21 & -0.01 & 0.85 & 1.00 & \\
\hline Medium & Poor & 0.21 & 0.76 & 0.24 & 1.10 & 0.02 & 0.82 & 1.10 & \\
\hline High & Good & 1.58 & 5.65 & 1.54 & 5.81 & 0.01 & 0.83 & 0.98 & \\
\hline High & Poor & 0.23 & 0.71 & 0.22 & 1.05 & 0.00 & 0.83 & 0.97 & \\
\hline \multicolumn{10}{|l|}{ Other forces } \\
\hline Low & Good & 0.06 & 0.99 & 0.06 & 1.06 & 0.00 & 0.12 & 1.10 & \\
\hline Low & Poor & 0.01 & 0.11 & 0.00 & 0.07 & 0.00 & 0.12 & 0.38 & \\
\hline Medium & Good & 0.01 & 0.23 & 0.01 & 0.28 & 0.00 & 0.05 & 1.23 & \\
\hline Medium & Poor & 0.00 & 0.01 & 0.00 & 0.00 & 0.00 & 0.01 & 0.00 & \\
\hline High & Good & 0.12 & 1.22 & 0.13 & 1.39 & 0.01 & 0.21 & 1.15 & $<0.05$ \\
\hline High & Poor & 0.02 & 0.26 & 0.01 & 0.17 & -0.01 & 0.21 & 0.41 & \\
\hline
\end{tabular}

a Delta: the difference between \% times obtained from the simultaneous method and the job-level method.

${ }^{b}$ Ratio: ratio of \% times obtained from the simultaneous method and the job-level method.

c Significance level notation: blank=not significant at $\mathrm{P}<0.05$ according to Wilcoxon Signed Ranks test.

${ }^{d} \mathrm{X} \%=(100-\mathrm{P} 1) /(100-\mathrm{P} 2)$, where $\mathrm{P} 1=$ good posture percentage, and $\mathrm{P} 2=$ poor posture percentage.

c show the results by different hand/wrist postures. In general, both methods were able to show that subjects of non-cases spent more time in non-forceful activities in good hand/wrist postures compared to CTS cases $(\mathrm{P}<0.01-0.05)$. There was a general trend that CTS cases spent more time on higher power and pinch grip forces, although the two methods did not always provide consistent results. For example, the job level combination analysis was able to find significant different of exertion times on high power grip force and poor wrist flexion/extension postures $(\mathrm{P}<0.05$, table $3 \mathrm{~b})$, but the simultaneous analysis method was not able to identify such relationship.

\section{Discussion}

This study demonstrated two methods of considering two risk factors (forceful exertions and hand/wrist postures) associated with a health outcome variable of work-related upper-extremity MSD (ie, CTS). The job-level combination risk factor analysis method has been more commonly used in MSD epidemiological studies $(1,3,4)$, while the simultaneous combination analysis method intuitively may illustrate the actual risk combinations in a job.

In a normal work day, workers usually perform many work-related activities with different types of forces at a variety of levels with varied hand/wrist postures. With 
Table 2c. Comparison of posture-exertion combination distributions between the job level and simultaneous analysis methods (wrist ulnar and radial deviation) $\mathrm{N}=733$. [SD=standard deviation.]

\begin{tabular}{|c|c|c|c|c|c|c|c|c|c|}
\hline \multirow{2}{*}{$\begin{array}{l}\text { Exertion type and category } \\
\text { (no, low, medium or } \\
\text { high exertion) }\end{array}$} & \multirow{2}{*}{$\begin{array}{l}\text { Posture } \\
\text { category }\end{array}$} & \multicolumn{2}{|c|}{$\%$ time } & \multicolumn{2}{|c|}{$\%$ time } & \multicolumn{2}{|c|}{ Delta $^{a}$} & \multirow[t]{2}{*}{ Ratio b $^{b}$} & \multirow[t]{2}{*}{$\mathrm{P}$-value } \\
\hline & & Job-level & $\mathrm{SD}$ & Simultaneous & SD & Mean & $\mathrm{SD}$ & & \\
\hline \multicolumn{10}{|l|}{ Non-forceful activity } \\
\hline No & Good & 80.14 & 18.15 & 80.67 & 17.78 & 0.45 & 2.71 & 1.01 & $<0.001$ \\
\hline No & Poor & 4.18 & 5.12 & 3.80 & 5.01 & -0.33 & 2.07 & 0.91 & $<0.001$ \\
\hline \multicolumn{10}{|c|}{ Non-forceful activity $(100-X \%)^{d}$} \\
\hline No & Good & 19.86 & 18.15 & 19.33 & 17.78 & -0.45 & 2.71 & 0.97 & $<0.001$ \\
\hline \multicolumn{10}{|l|}{ Lift/lower } \\
\hline Low & Good & 3.62 & 9.18 & 3.58 & 9.18 & -0.09 & 1.00 & 0.99 & $<0.05$ \\
\hline Low & Poor & 0.20 & 0.62 & 0.29 & 1.25 & 0.10 & 0.95 & 1.49 & \\
\hline Medium & Good & 1.81 & 5.22 & 1.77 & 5.04 & 0.02 & 0.61 & 0.98 & $<0.001$ \\
\hline Medium & Poor & 0.11 & 0.44 & 0.10 & 0.70 & -0.01 & 0.61 & 0.84 & $<0.001$ \\
\hline High & Good & 1.89 & 4.99 & 1.87 & 5.00 & 0.00 & 0.47 & 0.99 & $<0.001$ \\
\hline High & Poor & 0.11 & 0.53 & 0.11 & 0.72 & 0.00 & 0.45 & 1.01 & $<0.001$ \\
\hline \multicolumn{10}{|l|}{ Push/pull } \\
\hline Low & Good & 0.29 & 2.55 & 0.30 & 2.67 & 0.01 & 0.17 & 1.06 & $<0.001$ \\
\hline Low & Poor & 0.02 & 0.29 & 0.02 & 0.26 & -0.01 & 0.12 & 0.74 & $P<0.01$ \\
\hline Medium & Good & 0.58 & 2.92 & 0.58 & 2.85 & 0.00 & 0.32 & 0.99 & $<0.001$ \\
\hline Medium & Poor & 0.03 & 0.19 & 0.02 & 0.25 & -0.01 & 0.13 & 0.54 & $<0.001$ \\
\hline High & Good & 0.46 & 2.21 & 0.45 & 2.18 & -0.02 & 0.35 & 0.98 & $<0.05$ \\
\hline High & Poor & 0.02 & 0.12 & 0.02 & 0.25 & 0.00 & 0.23 & 0.99 & $<0.001$ \\
\hline \multicolumn{10}{|l|}{ Power grip } \\
\hline Low & Good & 0.38 & 2.49 & 0.37 & 2.50 & -0.02 & 0.35 & 0.96 & \\
\hline Low & Poor & 0.02 & 0.16 & 0.05 & 0.43 & 0.02 & 0.35 & 2.04 & \\
\hline Medium & Good & 1.63 & 6.96 & 1.58 & 6.98 & -0.05 & 0.69 & 0.97 & \\
\hline Medium & Poor & 0.10 & 0.51 & 0.15 & 0.95 & 0.05 & 0.70 & 1.51 & \\
\hline High & Good & 0.77 & 3.43 & 0.74 & 3.41 & -0.04 & 0.49 & 0.97 & \\
\hline High & Poor & 0.05 & 0.38 & 0.09 & 0.72 & 0.04 & 0.49 & 1.82 & \\
\hline \multicolumn{10}{|l|}{ Pinch grip } \\
\hline Low & Good & 0.07 & 1.20 & 0.08 & 1.25 & 0.00 & 0.08 & 1.07 & \\
\hline Low & Poor & 0.01 & 0.06 & 0.00 & 0.07 & 0.00 & 0.08 & 0.43 & \\
\hline Medium & Good & 1.27 & 4.23 & 1.26 & 4.17 & -0.04 & 0.60 & 0.99 & $<0.05$ \\
\hline Medium & Poor & 0.09 & 0.42 & 0.13 & 0.79 & 0.04 & 0.58 & 1.43 & \\
\hline High & Good & 1.69 & 5.72 & 1.64 & 5.80 & 0.00 & 0.65 & 0.97 & $<0.001$ \\
\hline High & Poor & 0.12 & 0.64 & 0.12 & 0.83 & 0.01 & 0.64 & 1.01 & $<0.001$ \\
\hline \multicolumn{10}{|l|}{ Other forces } \\
\hline Low & Good & 0.06 & 0.97 & 0.04 & 0.56 & -0.02 & 0.44 & 0.66 & \\
\hline Low & Poor & 0.01 & 0.08 & 0.03 & 0.52 & 0.02 & 0.44 & 5.18 & \\
\hline Medium & Good & 0.01 & 0.23 & 0.01 & 0.28 & 0.00 & 0.05 & 1.18 & \\
\hline Medium & Poor & 0.00 & 0.00 & 0.00 & 0.00 & 0.00 & 0.00 & 0.00 & \\
\hline High & Good & 0.13 & 1.44 & 0.14 & 1.48 & 0.00 & 0.08 & 1.04 & $<0.05$ \\
\hline High & Poor & 0.00 & 0.05 & 0.00 & 0.05 & 0.00 & 0.07 & 0.50 & \\
\hline
\end{tabular}

a Delta: the difference between \% times obtained from the simultaneous method and the job-level method.

${ }^{b}$ Ratio: ratio of \%times obtained from the simultaneous method and the job-level method.

c Significance level notation: blank=not significant at $\mathrm{P}<0.05$ according to Wilcoxon Signed Ranks test.

${ }^{d} \mathrm{X} \%=(100-\mathrm{P} 1) /(100-\mathrm{P} 2)$, where $\mathrm{P} 1=$ good posture percentage, and $\mathrm{P} 2=$ poor posture percentage.

the many different exposure variables and even more combinations of these variables, times spent on each of the combinations could be very low. This is particularly true for those high force and awkward posture combination exposure variables, as the majority time in modern workplaces people do various related activities which may not involve very significant forceful exertions in awkward postures. This is reflected in the present study, that, on average, times spent on high forces and awkward hand/wrist postures were very low (tables 2a, $b$, and c).

This may raise the question: from a physiological perspective, how important is the small amount of time spent on a particular high force exertion with awkward hand/wrist postures? For instance, only $0.05 \%$ (14.4 seconds in an 8-hour shift) or $0.09 \%$ (26 seconds) of time, depending on the combination analysis methods, were spent on high power grip force with poor wrist ulnar/radial deviation, table 2c). As a matter of fact, the results even showed a highly significant difference $(\mathrm{P}<0.01)$ on the times spent on the high power grip force with poor ulnar/radial deviation posture between the subjects of CTS case and non-case (table 3c) when using the job-level combination analysis. Although the difference was more than four times higher for the cases compared to the non-cases, the actual average durations 
Table 3a. Comparison of combination exposure between case and non-case using the two combination analysis methods (forearm pronation/supination). Number of cases=76, number of non-cases=644. [SD=standard deviation.]

\begin{tabular}{|c|c|c|c|c|c|c|c|c|c|c|c|c|c|c|c|}
\hline \multirow{2}{*}{$\begin{array}{l}\text { Exertion type and } \\
\text { category } \\
\text { (no, low, medium or } \\
\text { high exertion) }\end{array}$} & \multirow{2}{*}{$\begin{array}{l}\text { Posture } \\
\text { category }\end{array}$} & \multicolumn{7}{|c|}{ Job-level analysis method } & \multicolumn{7}{|c|}{ Simultaneous analysis method } \\
\hline & & $\begin{array}{l}\text { Non- } \\
\text { case }\end{array}$ & SD & Case & SD & Delta $^{a}$ & Ratio b $^{b}$ & $\overline{P \text {-value }}{ }^{c}$ & $\begin{array}{l}\text { Non- } \\
\text { case }\end{array}$ & SD & Case & SD & Delta $^{\text {a }}$ & Ratio b $^{b}$ & P-value ${ }^{c}$ \\
\hline \multicolumn{16}{|l|}{ Non-forceful activity } \\
\hline No & Good & 79.62 & 18.24 & 74.85 & 20.1 & -4.77 & 0.94 & $<0.05$ & 80.3 & 17.9 & 75.13 & 20.28 & -5.16 & 0.94 & $<0.05$ \\
\hline No & Poor & 5.26 & 5.43 & 5.05 & 5.26 & -0.21 & 0.96 & & 4.67 & 5.32 & 5.2 & 5.73 & 0.54 & 1.11 & \\
\hline \multicolumn{16}{|l|}{$\begin{array}{l}\text { Non-forceful activity } \\
(100-X \%)^{d}\end{array}$} \\
\hline No & Good & 20.38 & 18.24 & 25.15 & 20.1 & 4.77 & 1.23 & $<0.05$ & 19.7 & 17.9 & 24.87 & 20.28 & 5.16 & 1.26 & $<0.05$ \\
\hline \multicolumn{16}{|l|}{ Lift/lower } \\
\hline Low & Good & 3.49 & 8.76 & 3.91 & 10.22 & 0.42 & 1.12 & & 3.24 & 8.34 & 3.85 & 10.77 & 0.60 & 1.19 & \\
\hline Low & Poor & 0.32 & 1.10 & 0.29 & 0.82 & -0.03 & 0.91 & & 0.59 & 2.17 & 0.35 & 0.97 & -0.24 & 0.59 & \\
\hline Medium & Good & 1.65 & 4.68 & 2.00 & 4.11 & 0.36 & 1.22 & & 1.46 & 4.46 & 1.91 & 3.95 & 0.45 & 1.31 & $<0.05$ \\
\hline Medium & Poor & 0.17 & 0.75 & 0.18 & 0.50 & 0.01 & 1.05 & & 0.37 & 1.40 & 0.28 & 1.04 & -0.09 & 0.76 & \\
\hline High & Good & 1.72 & 4.32 & 2.42 & 7.93 & 0.70 & 1.41 & & 1.44 & 3.74 & 2.15 & 7.52 & 0.72 & 1.50 & \\
\hline High & Poor & 0.19 & 0.62 & 0.22 & 0.70 & 0.03 & 1.18 & & 0.47 & 1.84 & 0.49 & 2.00 & 0.02 & 1.05 & \\
\hline \multicolumn{16}{|l|}{ Push/pull } \\
\hline Low & Good & 0.24 & 2.10 & 0.69 & 4.89 & 0.45 & 2.87 & & 0.25 & 2.29 & 0.62 & 4.19 & 0.37 & 2.48 & \\
\hline Low & Poor & 0.02 & 0.21 & 0.08 & 0.66 & 0.06 & 4.41 & & 0.02 & 0.29 & 0.16 & 1.38 & 0.14 & 9.40 & \\
\hline Medium & Good & 0.47 & 2.03 & 1.35 & 6.60 & 0.88 & 2.89 & & 0.46 & 2.06 & 1.26 & 6.34 & 0.80 & 2.74 & \\
\hline Medium & Poor & 0.03 & 0.20 & 0.09 & 0.46 & 0.06 & 2.71 & & 0.04 & 0.34 & 0.07 & 0.48 & 0.03 & 1.79 & \\
\hline High & Good & 0.45 & 2.23 & 0.45 & 1.48 & 0.00 & 0.99 & & 0.45 & 2.26 & 0.42 & 1.20 & -0.03 & 0.93 & \\
\hline High & Poor & 0.04 & 0.20 & 0.02 & 0.10 & -0.01 & 0.66 & & 0.02 & 0.25 & 0.00 & 0.00 & -0.02 & 0.00 & \\
\hline \multicolumn{16}{|l|}{ Power grip } \\
\hline Low & Good & 0.35 & 2.34 & 0.63 & 2.63 & 0.28 & 1.80 & & 0.32 & 2.23 & 0.59 & 2.55 & 0.27 & 1.84 & \\
\hline Low & Poor & 0.03 & 0.33 & 0.02 & 0.10 & -0.01 & 0.73 & & 0.06 & 0.79 & 0.07 & 0.41 & 0.01 & 1.08 & \\
\hline Medium & Good & 1.60 & 6.78 & 2.03 & 9.51 & 0.43 & 1.27 & & 1.63 & 6.94 & 2.06 & 9.53 & 0.43 & 1.27 & \\
\hline Medium & Poor & 0.09 & 0.43 & 0.05 & 0.20 & -0.04 & 0.56 & & 0.07 & 0.58 & 0.04 & 0.31 & -0.03 & 0.50 & \\
\hline High & Good & 0.68 & 3.22 & 1.49 & 5.11 & 0.81 & 2.18 & $<0.05$ & 0.69 & 3.22 & 1.53 & 5.36 & 0.83 & 2.20 & $<0.01$ \\
\hline High & Poor & 0.06 & 0.32 & 0.10 & 0.35 & 0.04 & 1.72 & $<0.01$ & 0.05 & 0.54 & 0.06 & 0.32 & 0.01 & 1.24 & \\
\hline \multicolumn{16}{|l|}{ Pinch grip } \\
\hline Low & Good & 0.08 & 1.28 & 0.04 & 0.32 & -0.04 & 0.46 & & 0.08 & 1.30 & 0.04 & 0.32 & -0.04 & 0.48 & \\
\hline Low & Poor & 0.00 & 0.05 & 0.00 & 0.00 & 0.00 & 0.10 & & 0.01 & 0.16 & 0.00 & 0.00 & -0.01 & 0.00 & \\
\hline Medium & Good & 1.23 & 4.24 & 1.86 & 4.99 & 0.63 & 1.51 & $<0.05$ & 1.20 & 4.21 & 1.92 & 5.27 & 0.72 & 1.60 & $<0.05$ \\
\hline Medium & Poor & 0.09 & 0.42 & 0.13 & 0.41 & 0.05 & 1.56 & $<0.05$ & 0.12 & 0.72 & 0.10 & 0.63 & -0.01 & 0.88 & \\
\hline High & Good & 1.59 & 5.56 & 1.45 & 3.96 & -0.15 & 0.91 & & 1.53 & 5.65 & 1.50 & 4.32 & -0.02 & 0.98 & \\
\hline High & Poor & 0.18 & 0.99 & 0.14 & 0.50 & -0.04 & 0.78 & & 0.26 & 1.41 & 0.10 & 0.71 & -0.16 & 0.38 & \\
\hline \multicolumn{16}{|l|}{ Other forces } \\
\hline Low & Good & 0.07 & 1.07 & 0.04 & 0.35 & -0.03 & 0.60 & & 0.06 & 0.96 & 0.04 & 0.36 & -0.02 & 0.68 & \\
\hline Low & Poor & 0.00 & 0.05 & 0.00 & 0.01 & 0.00 & 0.32 & & 0.01 & 0.18 & 0.00 & 0.00 & -0.01 & 0.00 & \\
\hline Medium & Good & 0.01 & 0.23 & 0.03 & 0.26 & 0.02 & 3.34 & & 0.01 & 0.25 & 0.03 & 0.30 & 0.02 & 3.51 & \\
\hline Medium & Poor & 0.00 & 0.01 & 0.00 & 0.04 & 0.00 & 17.92 & & 0.00 & 0.00 & 0.00 & 0.00 & 0.00 & $\mathrm{NaN}$ & \\
\hline High & Good & 0.14 & 1.44 & 0.03 & 0.30 & -0.11 & 0.24 & & 0.13 & 1.30 & 0.03 & 0.30 & -0.10 & 0.26 & \\
\hline High & Poor & 0.01 & 0.15 & 0.00 & 0.00 & -0.01 & 0.04 & & 0.02 & 0.40 & 0.00 & 0.00 & -0.02 & 0.00 & \\
\hline
\end{tabular}

a Delta: the difference between \% times obtained from the simultaneous method and the job-level method.

${ }^{b}$ Ratio: ratio of \%times obtained from the simultaneous method and the job-level method.

c Significance level notation: blank=not significant at $\mathrm{P}<0.05$ according to Mann-Whitney test.

${ }^{d} \mathrm{X} \%=(100-\mathrm{P} 1) /(100-\mathrm{P} 2)$, where $\mathrm{P} 1=$ good posture percentage, and $\mathrm{P} 2=$ poor posture percentage.

were only 46 seconds (for an 8 -hour work shift) for the cases compared to 12 seconds for the non-cases.

Since the present paper was mainly aimed at introducing the simultaneous combination analysis method, we will not spend too much time on discussions of the physiological importance of such short durations of these combined. In reality, to improve the physiological importance of certain high hand force and postural exertions, we may need to combine some of the exposures such as several high forces (lifting/lowering, power gripping and pinch gripping) and several poor hand/wrist postures (flexion/extension and ulnar/radial deviation). Further research on the physiological significance of combined force and posture risk factors is needed to determine the cut-off points for exposure-response modeling.

There were often statistically significant differences in terms of times spent on the different forceful exertion and hand/wrist posture combination categories between the two types of combination analysis methods (tables 2a, $\mathrm{b}$, and $\mathrm{c}$ ). These differences confirm our hypothesis that the commonly used job-level risk combination analysis method does not really reflect the reality of combined physical exposures in workplaces. The differences may depend on the types of forces and the hand/wrist pos- 
Table 3b. Comparison of combination exposure between case and non-case using the two combination analysis methods (wrist flexion and extension), number of cases=76, number of non-cases=644. [SD=standard deviation.]

\begin{tabular}{|c|c|c|c|c|c|c|c|c|c|c|c|c|c|c|c|}
\hline \multirow{2}{*}{$\begin{array}{l}\text { Exertion type and } \\
\text { category (no, low, } \\
\text { medium or high } \\
\text { exertion) }\end{array}$} & \multirow{2}{*}{$\begin{array}{l}\text { Posture } \\
\text { category }\end{array}$} & \multicolumn{7}{|c|}{ Job-level analysis method } & \multicolumn{7}{|c|}{ Simultaneous analysis method } \\
\hline & & Non-case & SD & Case & SD & Delta $^{a}$ & Ratio b & $P$-value ${ }^{c}$ & Non-case & SD & Case & SD & Delta $^{\text {a }}$ & Ratio $^{b}$ & $P$-value ${ }^{c}$ \\
\hline \multicolumn{16}{|l|}{ Non-forceful activity } \\
\hline No & Good & 72.24 & 17.83 & 66.78 & 18.48 & -5.46 & 0.92 & $<0.05$ & 72.86 & 17.76 & 67.72 & 18.83 & -5.14 & 0.93 & $<0.05$ \\
\hline No & Poor & 12.63 & 8.95 & 13.11 & 8.56 & 0.48 & 1.04 & & 12.09 & 9.41 & 12.6 & 9.07 & 0.52 & 1.04 & \\
\hline \multicolumn{16}{|l|}{$\begin{array}{l}\text { Non-forceful activity } \\
(100-\mathrm{X} \%)^{d}\end{array}$} \\
\hline No & Good & 27.76 & 17.83 & 33.22 & 18.48 & 5.46 & 1.20 & $<0.05$ & 27.14 & 17.76 & 32.28 & 18.83 & 5.14 & 1.19 & $<0.05$ \\
\hline \multicolumn{16}{|l|}{ Lift/lower } \\
\hline Low & Good & 3.25 & 8.46 & 3.54 & 9.90 & 0.29 & 1.09 & & 3.17 & 8.25 & 3.57 & 10.08 & 0.40 & 1.13 & \\
\hline Low & Poor & 0.56 & 1.40 & 0.67 & 1.68 & 0.10 & 1.18 & & 0.66 & 1.95 & 0.62 & 1.58 & -0.03 & 0.95 & \\
\hline Medium & Good & 1.55 & 4.51 & 1.87 & 3.90 & 0.33 & 1.21 & & 1.52 & 4.55 & 1.85 & 3.57 & 0.33 & 1.22 & \\
\hline Medium & Poor & 0.28 & 0.92 & 0.32 & 0.66 & 0.04 & 1.14 & & 0.31 & 1.16 & 0.34 & 1.45 & 0.04 & 1.12 & \\
\hline High & Good & 1.59 & 4.11 & 2.31 & 7.63 & 0.72 & 1.46 & & 1.52 & 4.14 & 2.19 & 7.52 & 0.67 & 1.44 & \\
\hline High & Poor & 0.32 & 0.94 & 0.33 & 0.89 & 0.01 & 1.05 & & 0.38 & 1.43 & 0.45 & 1.62 & 0.07 & 1.18 & \\
\hline \multicolumn{16}{|l|}{ Push/pull } \\
\hline Low & Good & 0.20 & 1.66 & 0.59 & 4.15 & 0.40 & 3.00 & & 0.19 & 1.80 & 0.57 & 4.16 & 0.39 & 3.09 & \\
\hline Low & Poor & 0.06 & 0.68 & 0.18 & 1.40 & 0.12 & 2.95 & & 0.08 & 0.69 & 0.20 & 1.40 & 0.12 & 2.52 & \\
\hline Medium & Good & 0.41 & 1.82 & 1.23 & 6.05 & 0.82 & 2.97 & & 0.40 & 1.85 & 1.16 & 5.87 & 0.76 & 2.90 & \\
\hline Medium & Poor & 0.09 & 0.42 & 0.21 & 1.02 & 0.12 & 2.42 & & 0.10 & 0.68 & 0.17 & 0.98 & 0.07 & 1.69 & \\
\hline High & Good & 0.40 & 1.96 & 0.38 & 1.21 & -0.03 & 0.94 & & 0.37 & 1.92 & 0.33 & 1.04 & -0.04 & 0.89 & \\
\hline High & Poor & 0.09 & 0.46 & 0.10 & 0.35 & 0.01 & 1.10 & & 0.10 & 0.77 & 0.09 & 0.40 & -0.01 & 0.86 & \\
\hline \multicolumn{16}{|l|}{ Power grip } \\
\hline Low & Good & 0.31 & 2.05 & 0.48 & 1.96 & 0.17 & 1.53 & & 0.32 & 2.01 & 0.56 & 2.28 & 0.24 & 1.76 & \\
\hline Low & Poor & 0.07 & 0.58 & 0.17 & 0.84 & 0.11 & 2.54 & & 0.06 & 0.73 & 0.10 & 0.60 & 0.03 & 1.52 & \\
\hline Medium & Good & 1.46 & 6.23 & 1.71 & 8.05 & 0.26 & 1.18 & & 1.36 & 5.87 & 1.73 & 7.71 & 0.36 & 1.27 & \\
\hline Medium & Poor & 0.24 & 1.07 & 0.37 & 1.58 & 0.13 & 1.55 & & 0.33 & 1.97 & 0.37 & 1.91 & 0.03 & 1.10 & \\
\hline High & Good & 0.62 & 2.99 & 1.37 & 4.72 & 0.75 & 2.22 & $<0.01$ & 0.63 & 3.07 & 1.43 & 5.06 & 0.81 & 2.29 & $<0.05$ \\
\hline High & Poor & 0.12 & 0.64 & 0.22 & 0.76 & 0.09 & 1.76 & $<0.05$ & 0.12 & 0.74 & 0.16 & 0.65 & 0.04 & 1.33 & \\
\hline \multicolumn{16}{|l|}{ Pinch grip } \\
\hline Low & Good & 0.07 & 1.24 & 0.03 & 0.24 & -0.05 & 0.38 & & 0.07 & 1.31 & 0.04 & 0.32 & -0.04 & 0.49 & \\
\hline Low & Poor & 0.01 & 0.10 & 0.01 & 0.08 & 0.00 & 0.97 & & 0.01 & 0.15 & 0.00 & 0.00 & -0.01 & 0.00 & \\
\hline Medium & Good & 1.10 & 3.91 & 1.74 & 4.84 & 0.64 & 1.58 & $<0.05$ & 1.08 & 4.06 & 1.80 & 5.30 & 0.73 & 1.67 & $<0.05$ \\
\hline Medium & Poor & 0.21 & 0.78 & 0.26 & 0.68 & 0.04 & 1.20 & $<0.05$ & 0.24 & 1.10 & 0.22 & 1.05 & -0.02 & 0.92 & \\
\hline High & Good & 1.55 & 5.77 & 1.38 & 3.88 & -0.17 & 0.89 & & 1.55 & 5.97 & 1.45 & 4.18 & -0.10 & 0.94 & \\
\hline High & Poor & 0.22 & 0.71 & 0.21 & 0.53 & -0.01 & 0.94 & & 0.23 & 1.10 & 0.15 & 0.58 & -0.08 & 0.64 & \\
\hline \multicolumn{16}{|l|}{ Other forces } \\
\hline Low & Good & 0.06 & 1.05 & 0.04 & 0.31 & -0.03 & 0.58 & & 0.07 & 1.12 & 0.04 & 0.36 & -0.03 & 0.62 & \\
\hline Low & Poor & 0.01 & 0.12 & 0.01 & 0.05 & 0.00 & 0.67 & & 0.00 & 0.08 & 0.00 & 0.00 & 0.00 & 0.00 & \\
\hline Medium & Good & 0.01 & 0.23 & 0.03 & 0.26 & 0.02 & 3.24 & & 0.01 & 0.28 & 0.03 & 0.30 & 0.02 & 3.07 & \\
\hline Medium & Poor & 0.00 & 0.00 & 0.00 & 0.04 & 0.00 & 41.56 & & 0.00 & 0.00 & 0.00 & 0.00 & 0.00 & $\mathrm{~N} / \mathrm{A}$ & \\
\hline High & Good & 0.13 & 1.30 & 0.03 & 0.26 & -0.10 & 0.23 & & 0.14 & 1.46 & 0.03 & 0.30 & -0.11 & 0.24 & \\
\hline High & Poor & 0.03 & 0.28 & 0.01 & 0.04 & -0.02 & 0.20 & & 0.01 & 0.17 & 70.00 & 0.00 & -0.01 & 0.00 & \\
\hline
\end{tabular}

ture in concern. For example, the job-level combination analysis seemed to underestimate the times spent on the high lifting/lowering in combination with poor pronation/ supination posture (table 2a). The simultaneous combination analysis showed that heavy lifting/lowering might have often forced the forearm into awkward postures. On the other hand, the job-level combination analysis might have overestimated the time spent on high power grip with poor forearm supination/pronation posture compared to the simultaneous combination analysis (table 2a). The simultaneous combination analysis showed that workers might often have the ability to use better forearm postures in performing tasks that required high power grip forces.

It might need to be noted that, although statistically significant different, most of the differences between the job-level and simultaneous differences were small in terms of magnitude (eg, high pinch grip force with poor wrist ulnar/radial deviation posture and medium push/ pull force in poor wrist ulnar/radial deviation posture in table 2c). This means that a researcher/practitioner wishing to know about combination exposures may use the simpler method for assessing each factor (the joblevel combination) rather than the more complicated method (the simultaneous combination) with a satisfac- 
Table 3c. Comparison of combination exposure between case and non-case using the two combination analysis methods (wrist ulnar and radial deviation) number of cases=76, number of non-cases=644. [SD=standard deviation.]

\begin{tabular}{|c|c|c|c|c|c|c|c|c|c|c|c|c|c|c|c|}
\hline \multirow{2}{*}{$\begin{array}{l}\text { Exertion type and } \\
\text { category } \\
\text { (no, low, medium or } \\
\text { high exertion) }\end{array}$} & \multirow{2}{*}{$\begin{array}{l}\text { Posture } \\
\text { Category }\end{array}$} & \multicolumn{7}{|c|}{ Job-level analysis method } & \multicolumn{7}{|c|}{ Simultaneous analysis method } \\
\hline & & $\begin{array}{l}\text { Non- } \\
\text { case }\end{array}$ & SD & Case & SD & Delta $^{\text {a }}$ & Ratio $^{b}$ & $\overline{P \text {-value }}{ }^{c}$ & $\begin{array}{l}\text { Non- } \\
\text { case }\end{array}$ & SD & Control & SD & Delta $^{a}$ & Ratio $^{b}$ & P-value ${ }^{c}$ \\
\hline \multicolumn{16}{|l|}{ Non forceful activity } \\
\hline No & Good & 80.88 & 17.78 & 74.64 & 19.51 & -6.24 & 0.92 & $<0.01$ & 81.27 & 17.54 & 75.56 & 19.03 & -5.71 & 0.93 & $<0.01$ \\
\hline No & Poor & 3.99 & 4.97 & 5.25 & 5.20 & 1.26 & 1.32 & $<0.05$ & 3.68 & 4.91 & 4.77 & 5.68 & 1.09 & 1.30 & \\
\hline \multicolumn{16}{|l|}{$\begin{array}{l}\text { Non forceful activity } \\
(100-X \%)\end{array}$} \\
\hline No & Good & 19.12 & 17.78 & 25.36 & 19.51 & 6.24 & 1.33 & $<0.01$ & 18.73 & 17.54 & 24.44 & 19.03 & 5.71 & 1.30 & $<0.01$ \\
\hline \multicolumn{16}{|l|}{ Lift/Lower } \\
\hline Low & Good & 3.62 & 9.04 & 4.04 & 10.83 & 0.42 & 1.12 & & 3.53 & 8.95 & 3.98 & 10.95 & 0.45 & 1.13 & \\
\hline Low & Poor & 0.20 & 0.65 & 0.17 & 0.39 & -0.03 & 0.86 & & 0.30 & 1.29 & 0.21 & 0.80 & -0.09 & 0.71 & \\
\hline Medium & Good & 1.72 & 5.04 & 2.02 & 4.19 & 0.30 & 1.17 & & 1.76 & 5.19 & 1.87 & 3.63 & 0.11 & 1.06 & \\
\hline Medium & Poor & 0.10 & 0.39 & 0.17 & 0.51 & 0.07 & 1.69 & & 0.07 & 0.43 & 0.32 & 1.75 & 0.25 & 4.71 & \\
\hline High & Good & 1.82 & 4.64 & 2.36 & 7.19 & 0.54 & 1.30 & & 1.82 & 4.73 & 2.32 & 6.90 & 0.50 & 1.27 & \\
\hline High & Poor & 0.09 & 0.30 & 0.28 & 1.39 & 0.19 & 3.19 & & 0.08 & 0.45 & 0.33 & 1.79 & 0.24 & 3.89 & \\
\hline \multicolumn{16}{|l|}{ Push/Pull } \\
\hline Low & Good & 0.24 & 2.00 & 0.74 & 5.39 & 0.51 & 3.14 & & 0.25 & 2.09 & 0.78 & 5.55 & 0.53 & 3.14 & \\
\hline Low & Poor & 0.02 & 0.31 & 0.03 & 0.17 & 0.01 & 1.39 & & 0.02 & 0.28 & 0.00 & 0.00 & -0.02 & 0.00 & \\
\hline Medium & Good & 0.48 & 2.11 & 1.34 & 6.57 & 0.86 & 2.78 & & 0.50 & 2.15 & 1.25 & 6.13 & 0.76 & 2.53 & \\
\hline Medium & Poor & 0.02 & 0.10 & 0.10 & 0.51 & 0.08 & 5.39 & & 0.01 & 0.12 & 0.08 & 0.69 & 0.07 & 10.56 & \\
\hline High & Good & 0.47 & 2.30 & 0.45 & 1.47 & -0.02 & 0.95 & & 0.45 & 2.27 & 0.40 & 1.18 & -0.05 & 0.89 & \\
\hline High & Poor & 0.02 & 0.12 & 0.03 & 0.10 & 0.01 & 1.39 & & 0.02 & 0.26 & 0.02 & 0.15 & 0.00 & 0.84 & \\
\hline \multicolumn{16}{|l|}{ Power Grip } \\
\hline Low & Good & 0.36 & 2.51 & 0.61 & 2.52 & 0.25 & 1.68 & & 0.34 & 2.49 & 0.62 & 2.57 & 0.28 & 1.83 & \\
\hline Low & Poor & 0.02 & 0.15 & 0.05 & 0.25 & 0.03 & 2.26 & & 0.05 & 0.44 & 0.04 & 0.36 & -0.01 & 0.89 & \\
\hline Medium & Good & 1.59 & 6.67 & 2.00 & 9.37 & 0.41 & 1.26 & & 1.54 & 6.65 & 1.93 & 9.35 & 0.39 & 1.25 & \\
\hline Medium & Poor & 0.10 & 0.54 & 0.08 & 0.27 & -0.02 & 0.79 & & 0.15 & 0.91 & 0.16 & 1.25 & 0.01 & 1.04 & \\
\hline High & Good & 0.70 & 3.28 & 1.43 & 4.69 & 0.73 & 2.04 & $<0.01$ & 0.67 & 3.26 & 1.33 & 4.41 & 0.66 & 1.98 & $<0.05$ \\
\hline High & Poor & 0.04 & 0.28 & 0.16 & 0.85 & 0.12 & 4.12 & $<0.01$ & 0.07 & 0.58 & 0.26 & 1.43 & 0.18 & 3.57 & $<0.05$ \\
\hline \multicolumn{16}{|l|}{ Pinch Grip } \\
\hline Low & Good & 0.08 & 1.28 & 0.03 & 0.25 & -0.05 & 0.38 & & 0.08 & 1.32 & 0.04 & 0.32 & -0.04 & 0.46 & \\
\hline Low & Poor & 0.01 & 0.06 & 0.01 & 0.06 & 0.00 & 1.28 & & 0.00 & 0.07 & 0.00 & 0.00 & 0.00 & 0.00 & \\
\hline Medium & Good & 1.23 & 4.20 & 1.83 & 4.76 & 0.60 & 1.49 & $<0.05$ & 1.21 & 4.11 & 1.69 & 4.61 & 0.48 & 1.40 & \\
\hline Medium & Poor & 0.08 & 0.40 & 0.17 & 0.64 & 0.08 & 1.97 & $<0.01$ & 0.11 & 0.68 & 0.33 & 1.39 & 0.23 & 3.12 & \\
\hline High & Good & 1.66 & 5.82 & 1.49 & 4.20 & -0.17 & 0.90 & & 1.67 & 5.96 & 1.44 & 4.28 & -0.23 & 0.86 & \\
\hline High & Poor & 0.11 & 0.66 & 0.10 & 0.28 & -0.02 & 0.84 & & 0.11 & 0.85 & 0.16 & 0.69 & 0.05 & 1.40 & \\
\hline \multicolumn{16}{|l|}{ Other Forces } \\
\hline Low & Good & 0.06 & 1.04 & 0.03 & 0.29 & -0.03 & 0.51 & & 0.04 & 0.58 & 0.04 & 0.36 & 0.00 & 1.04 & \\
\hline Low & Poor & 0.00 & 0.09 & 0.01 & 0.07 & 0.00 & 1.56 & & 0.03 & 0.55 & 0.00 & 0.00 & -0.03 & 0.00 & \\
\hline Medium & Good & 0.01 & 0.23 & 0.03 & 0.29 & 0.02 & 3.73 & & 0.01 & 0.28 & 0.03 & 0.30 & 0.02 & 3.07 & \\
\hline Medium & Poor & 0.00 & 0.00 & 0.00 & 0.00 & 0.00 & 3.78 & & 0.00 & 0.00 & 0.00 & 0.00 & 0.00 & $\mathrm{~N} / \mathrm{A}$ & \\
\hline High & Good & 0.15 & 1.53 & 0.03 & 0.30 & -0.11 & 0.23 & & 0.15 & 1.57 & 0.03 & 0.30 & -0.12 & 0.23 & \\
\hline High & Poor & 0.00 & 0.06 & 0.00 & 0.00 & 0.00 & 0.00 & & 0.00 & 0.05 & 0.00 & 0.00 & 0.00 & 0.00 & \\
\hline
\end{tabular}

tory degree (often more than $80 \%$ of the time). Figure 2 shows two examples of comparisons of the forceful exertion and hand/wrist posture combination results. Due to the assumption used in the job-level combination analysis, it systematically overestimated the combination risk factors when it actually did not even occur as shown in the simultaneous combination analysis. Werner et al (23) found that wrist ulnar/radial deviation was significantly related to CTS among automobile assembly workers, although job-level rated peak hand force was not statistically significant in their analyses. Keir et al (24) did an experimental study comparing carpal tunnel pressures using a pinch grip and a pressing force. They found that the internal loading, as measured by carpal tunnel pressure, experienced a near 2-fold increase using a pinch grip. Using cadaveric wrists, Keir et al (25) noted that carpal tunnel pressure increased with awkward wrist postures. High carpal tunnel pressure is linked to CTS (26). Measuring intramuscular pressure actually considers both external hand force and hand/ wrist postures through the consideration of the internal exposure. This method bypasses the consideration of simultaneous combination of external force and hand/ wrist posture. It would be good to use the internal expo- 

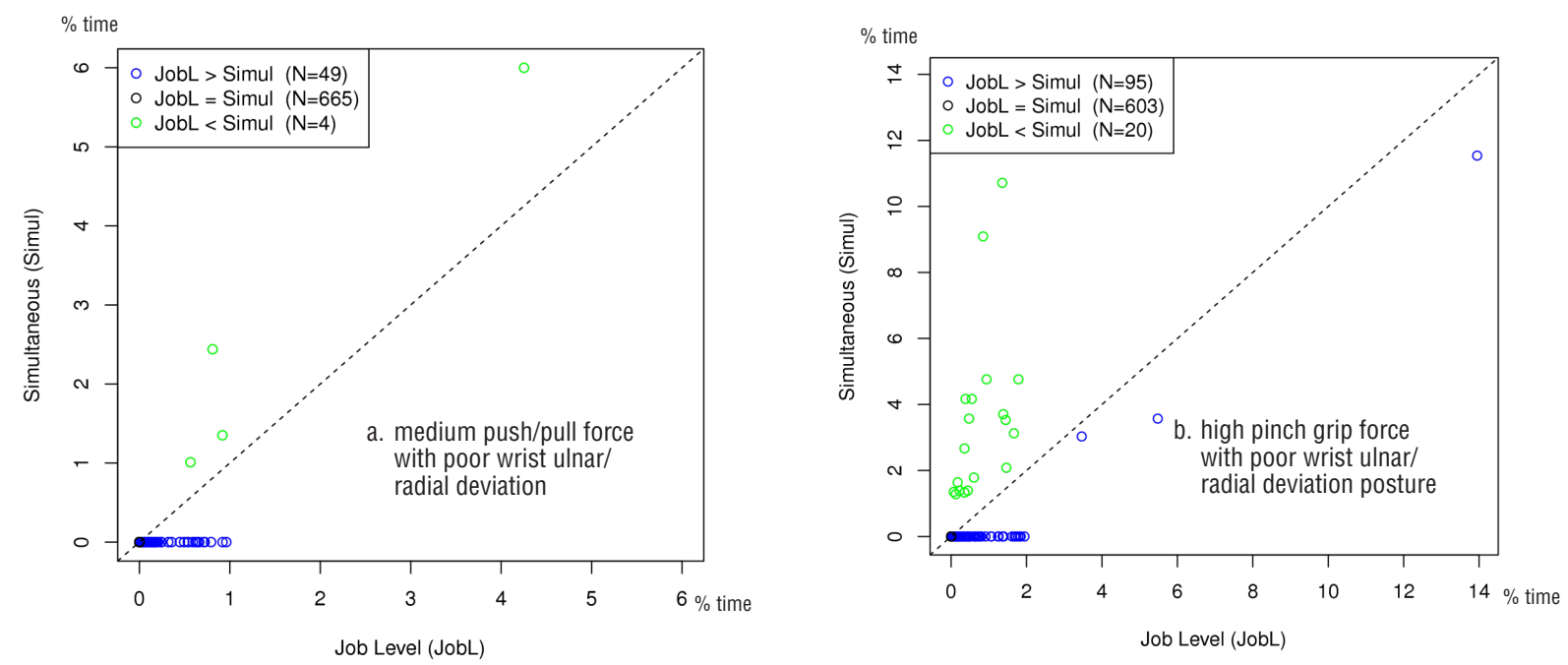

Figure 2. Comparison of results obtained by the job-level combination and simultaneous combination analysis methods; (a) medium push/pull force in combination with poor wrist ulnar/radial deviation posture, and (b) high pinch grip force with poor wrist ulnar/radial deviation posture.

sure in large epidemiological studies, although it might be unlikely feasible in large scale epidemiological studies due to its cost and complexity. All these studies seem to suggest that pinch grip force and/or awkward hand/ wrist postures are associated with CTS. More detailed information on combined force and hand/wrist posture from field epidemiological studies may help researchers understand better the relationships between the combined exposures and CTS problems.

Examining the forceful exertion and hand/wrist posture exposure distributions between subjects of cases and non-cases, both analysis methods indicated that subjects of non-cases spent more time in activities that involved non-forceful exertions with combination of good hand/wrist postures (tables 3a, b, and c). Both methods seem also to point to the direction that CTS cases spent more times in high power-grip forces and medium pinch-grip forces. This is in the line with the findings from the NIOSH review (10) that there is strong evidence for a relationship between exposure to a combination of risk factors and CTS.

It is difficult to see whether the job-level or simultaneous combination analysis method is more predictive in the present study. This is because that the number of subjects in the study population is not sufficient for the comparison. The power to detect differences with our sample sizes is limited. With 76 cases and 644 noncases, the detectable effect size using a t-test or a MannWhitney test even with normally distributed data is 0.34 or about one-third (using $80 \%$ power, 2 -sided tests and $\mathrm{P}<0.05$ ). Thus, we are likely to detect a case-control difference that is larger than about one-third of a standard deviation. Tables $3 \mathrm{a}, \mathrm{b}$, and $\mathrm{c}$ show differences of means between cases and non-cases that are generally smaller than one-third of a SD. Larger sample sizes would be needed to adequately test either the job-level or the simultaneous combination analysis method in studies of exposure-response relationships.

\section{Acknowledgements}

We acknowledge the important contributions of Ruby Irving, Benjamin Hamilton, Cindy Orr, Jessica Keller, and Larry Taing in assisting with the data collection in the field and data processing in the laboratory, and Caroline Smith in coordinating the field work. This research was funded in part by the US National Institute for Occupational Safety and Health (OH1007316) and the Washington State Department of Labor and Industries.

\section{References}

1. Punnett, L. Ergonomic stressors and upper extremity disorders in vehicle manufacturing: cross sectional exposure-response trends. Occup Environ Med. 1998;55:414-20. doi:10.1136/ oem.55.6.414.

2. Ariens, GA, PM Bongers, WE Hoogendoorn, G van der Wal, W van Mechelen. High physical and psychosocial load at work and sickness absence due to neck pain. Scand J Work Environ Health. 2002;28:222-31.

3. Punnett, L, J Gold, JN Katz, R Gore, DH Wegman. Ergonomic stressors and upper extremity musculoskeletal disorders in automobile manufacturing: a one year follow up study. Occup Environ Med. 2004;61:668-74. doi:10.1136/ oem.2003.008979.

Scand J Work Environ Health 2011, vol 37, no 6 
4. Silverstein, BA, SS Bao, ZJ Fan, N Howard, C Smith, P Spielholz et al. Rotator cuff syndrome: personal, work-related psychosocial and physical load factors. Occup Environ Med. 2008;50:1062-76. doi:10.1097/JOM.0b013e31817e7bdd.

5. Mirka, GA, DP Kelaher, DT Nay, BM Lawrence. Continuous assessment of back stress (CABS): a new method to quantify low-back stress in jobs with variable biomechanical demands. Hum Factors. 2000;42:209-25. doi:10.1518/001872000779656525.

6. Waters, TR, V Putz-Anderson, A Garg. Applications manual for the revised NIOSH lifting equation. In: U.S. Department of Health and Human Services Publish, Public Health Service; 1994.

7. The University of Michigan. 3D static strength prediction program (Version 6.0.0). Ann Arbor, Michigan: The University of Michigan, Center for Ergonomics; 2008.

8. Hansson, GA, I Balogh, K Ohlsson, B Palsson, L Rylander, S Skerfving. Impact of physical exposure on neck and upper limb disorders in female workers. Appl Ergon. 2000;31:301-10. doi:10.1016/S0003-6870(99)00047-2.

9. Bao, S, S Mathiassen, J Winkel. Ergonomic effects of a management-based rationalization in assembly work -- a case study. Appl Ergon. 1996;27:89-99. doi:10.1016/00036870(95)00063-1.

10. NIOSH. Musculoskeletal Disorders and Workplace Factors: A Critical Review of Epidemiologic Evidence for Work-Related Musculoskeletal Disorders of the Neck, Upper Extremity, and Low Back. Cincinnati, USA: National Institute for Occupational Safety and Health, DHHS; 1997.

11. Drury, CG. A biomechanical evaluation of the repetitive motion injury potential of industrial jobs. Seminars in Occupational Medicine. New York: Thieme Medical Publishers, Inc. 1987. p41-9.

12. Bao, S, B Silverstein, N Howard, P Spielholz. The Washington State SHARP approach to exposure assessment. In: Marras WS, Karwowski W. editor. Fundamentals and Assessment Tools for Occupational Ergonomics. Boca Raton, Florida: Taylor \& Francis Group; 2006. p1-22.

13. Silverstein, BA, E Viikari-Juntura, ZJ Fan, DK Bonauto, S Bao, C Smith. Natural course of nontraumatic rotator cuff tendinitis and shoulder symptoms in a working population. Scand J Work Environ Health. 2006;32:99-108.

14. Silverstein, B, ZJ Fan, CK Smith, S Bao, N Howard, P Spielholz et al. Gender adjustment or stratification in discerning upper extremity musculoskeletal disorder risk? Scand J Work Environ Health. 2009;35:113-26.
15. Bao, S, P Spielholz, N Howard, B Silverstein. Quantifying repetitive hand activity for epidemiological research on musculoskeletal disorders - part I: individual exposure assessment. Ergonomics. 2006;49:361-80. doi:10.1080/00140130500520214.

16. Bao, S, B Silverstein. Estimation of hand force in ergonomic job evaluations. Ergonomics. 2005;48:288-301. doi:10.1080/ 0014013042000327724.

17. Yen TY, RG Radwin. A Video-Based System for Acquiring Biomechanical Data Synchronized with Arbitrary Events and Activities. IEEE Trans Biomed Eng. 1995;42:944-8. doi:10.1109/10.412663.

18. Bao, S, N Howard, P Spielholz, B Silverstein. Inter-rater reliability of posture observation. Hum Factors. 2009;51:292309. doi: $10.1177 / 0018720809340273$.

19. Washington State Department of Labor and Industries. General occupational health standards, Chapter 296-62 WAC: Part A-1: Ergonomics (repealed), Olympia, WA, USA: Department of Labor and Industries; 2000.

20. McAtamney, L, EN Corlett. RULA: a survey method for the investigation of work-related upper limb disorders. Appl Ergon. 1993;24:91-9. doi:10.1016/0003-6870(93)90080-S.

21. Stetson, DS, WM Keyserling, BA Silverstein, JA Leonard. Observational analysis of the hand and wrist: a pilot study. Appl Occup Environ Hyg. 1991;6: 927-37.

22. Bao, S, N Howard, P Spielholz, B Silverstein. Two posture analysis approaches and their application in a modified Rapid Upper Limb Assessment evaluation. Ergonomics. 2007: 1-19.

23. Werner, RA, A Franzblau, N Gell, AG Hartigan, M Ebersole, TJ Armstrong. Incidence of carpal tunnel syndrome among automobile assembly workers and assessment of risk factors. Occup Environ Med. 2005;47:1044-50. doi:10.1097/01. jom.0000171065.17288.a0.

24. Keir, PJ, JM Bach, DM Rempel. Fingertip loading and carpal tunnel pressure: differences between a pinching and a pressing task. J Orthop Res. 1998; 16:112-5. doi:10.1002/ jor.1100160119.

25. Keir, PJ, RP Wells, DA Ranney, W Lavery. The effects of tendon load and posture on carpal tunnel pressure. J Hand Surg Am. 1997;22:628-34. doi:10.1016/S0363-5023(97)80119-0.

26. Werner, RA, M Andary. Carpal tunnel syndrome: pathophysiology and clinical neurophysiology. Clin Neurophysiol. 2002; 113: 1373-81. doi:10.1016/S13882457(02)00169-4.

Received for publication: 13 April 2010 